\author{
Lidia Mizak, Romuald Gryko, Aleksandra Nakonieczna, Tomasz Mirski \\ Jerzy Gaweł, Grzegorz Graniak, Bożena Wlizło-Skowronek, Paweł Rutyna \\ and Piotr Cieślik
}

\title{
4. METHODS OF SAMPLING
}

\subsection{Introduction}

The principal objective of sampling for biological agents is to provide the requirement for unambiguous agent identification in environmental media, food, water, or clinical samples.

The primary objective for sampling is that the strategy provides representative samples, that a sufficient number of samples are taken and that the sampling regime is in line with the physical properties of the suspected agent as well as the environment being sampled (e.g. soil, water, air etc.). Where to sample is also dependent on the weather conditions which should be measured and documented. The relevant samples taken should of course support accurate identification and quantification of the agent at appropriate concentrations that reflect both acute and chronic exposure dosages.

There is no standard procedure, which is recommended and described exactly, how a sampling tram should perform its task.

Sampling may be needed in order to:

- Identify the biological agent;

- Confirm the presence of a specific agent;

- Identify the source;

- Verify the occurrence of a crime;

- Formulate an appropriate response, for example support for medical personnel.

\subsection{Sampling plan}

A sampling plan or strategy is crucial for an efficient, secure and well documented sampling that is a prerequisite for an analysis that need to withstand forensic and legal requirements. The sampling methodology and procedures should be robust and repeatable. 
A sampling plan should include:

1. Input values: commands, limitations, infrastructure, terrain, immediate actions, purpose with sampling;

2. Risk assessment: threat scenario, agents, amounts, climate, population;

3. Implications: What samples should be collected, how to sample, protective measures, plan of evacuation, routines, scenario.

In addition to sampling equipment, portable devices which can record factual information during sample collection. Such equipment includes audio recorders, video cameras, GPS, and maps. It is also important to use weather stations to measure wind direction and temperature etc.

The essential protective equipment shall consist of:

- Protective clothing, first aid kits, antidote kits, antibiotics, and individual decontamination equipment;

- Biological detector kits where available;

- Biological warfare agent-related vaccinations or chemoprophylaxis, where available.

Canisters should be capped and placed into a plasticizer-free bag (or container). After expelling excess air, the bag should be closed and then sealed by taping.

\subsection{Sampling Sources}

During the sampling process should be select samples in areas which exhibit wet stains, powders, or particulate matter on surfaces, vegetation, water surfaces, or the ground. Less preferred sampling points are those exposed to direct sunlight and high temperatures and not exhibiting any visual indicators.

There are several types of samples or sample matrixes that can be encountered. Sampling may be performed from water, soil, sediments, air, vegetation, powder, liquid, dust, food and feed. In addition sampling may be performed in industries, upon detection or directly on suspicious goods.

Appropriate samples should be taken of the following categories:

Category 1. Unusual powders, liquids, defused munitions (including residues or fragments), NBC protective equipment, in particular respirator canisters and clothing, and (suspected) contaminated non-porous surfaces.

Category 2. Environmental samples including air, vegetation, soil, snow and water samples in the vicinity of the attacked area including food and drinking water.

Category 3. Biomedical samples, including physiological fluids such as blood, urine and saliva from presumed casualties or blood/tissue/organ samples from human and/or animal corpses. Arthropod vectors of disease such as mosquitoes, ticks etc. especially if noted in particularly large numbers and/or unusual geo-climatically sites. 


\subsubsection{Aerosol samples}

As aerosol we mean a suspension of solid or liquid particles (of the size of several microns) in a gaseous medium, usually air. It is formed in the process of aerosolization, which results in the formation of the so-called aerosol cloud.

Aerosols are one of the commonly used forms of application for a variety of agents of biological, chemical or radiological weapon used in a terrorist attack. The appearance of aerosols, smokes or sprays coming from aircraft, vehicles, shells or other ammunition is one of the indicators of the presence of biological, chemical or radiological factors on the potential battlefield. In addition, there may be a hidden attack because the diluted aerosol clouds of the agent may initially be undetectable by senses and may be used to contaminate of drinking water or food supplies. This hidden action may be a part of a terrorist strategy in sabotage attempts. Recognition of signs of aerosol formation may be crucial in a given emergency situation, but the hidden use of chemical, biological, or radiological (CBRN) agents is generally not possible for early detection.

Aerosols are one of the types of typical environmental samples. Aerosol samples should be taken when there is a strong presumption of residual airborne contamination, which must be confirmed with available CBRN detection equipment. NATO has developed procedures for sampling and identification of biological, chemical and radiological agents (SIBCRA). According to general scenarios developed by NATO, aerosols may contain chemical agents (mainly nervous and blistering) or biological agents (toxins, viruses and bacteria) and may enter the body through the skin, eyes or by inhalation route. Aerosol sampling procedures are performed in three operational phases after an attack: immediate, urgent and late. Sampling is required in the first two phases, while in the third phase is optional. Depending on the type of aerosol, guidelines for protective actions for sampling staff have also been developed. These actions include the provision of personnel equipment such as a manual chemical detector, low level oxygen and carbon monoxide portable monitors, skin protective clothing, HEPA and charcoal filters for respiratory protection, and self-contained breathing apparatus required at very high concentrations of factor in the air or oxygen depletion.

Sampling of aerosols in the immediate operational phase (during the first minutes to one hour after the onset of attack) is one of the method of evaluating the attack area (established by the emergency cordon) in terms of airborne contamination. For chemical agents, this assessment can be accomplished by simply observing of visible signs of contamination in combination with use of simple hand-held detection equipment or by sampling and immediate analysis in a field laboratory. For biological agents, airborne contamination can be assessed by observing of visible signs, using available detection equipment, or by sampling and immediate analysis in a field laboratory. For radiological agents, this assessment may be accomplished using appropriate procedures or by using an 
impromptu air sampling method. Detection or air sampling should be continue if the changes in the aerosol cloud or the release of a new agent will occur. If airborne contamination is detected outside the area of attack, the boundaries of the emergency cordon should be adjusted accordingly.

Aerosol sampling in an urgent operational phase (from several hours to several days after the onset of an attack) is intended to determine the type of CBRN agent that is present in the material and to assess the changes of location of the airborne contamination clouds. This, in turn, enables the military and political authorities to take effective protective actions and countermeasures to counter further direct exposure or inhalation of contamination and to initiate the process of attack site recovery.

Agents released in the form of aerosol or gas may leave little or no physical evidence of attack with their use (no potential casualties). However, useful samples may be taken from water, vegetation, and other materials such as protective equipment in the immediate attack area, where a particular agent may be absorbed. Sampling should be avoided in areas that are shielded by obstacles, as poor deposition of the agent may occur in these places. For biological and chemical agents, sampling should also be avoided in areas exposed to direct sunlight and high temperatures as these conditions promote rapid degradation of agents, especially biological agents. Ideally, when samples are obtained from shaded areas, and sometimes from buildings.

\section{General guidelines for air, smoke and aerosol sampling.}

The objective of air, smoke and aerosol sampling is to assess airborne contamination by CBRN agents, to assess exposure levels, verify of contamination cloud modelling, and implement of protective actions.

Filters and media for air samples may be evaluated in field laboratories deployed in the attack area or in laboratories remote from the attack site, respectively. Field laboratory analyses can provide confirmed agent identification and precisely determine the agent-specific levels in the air. Analyses in remote laboratories can provide unequivocal identification of the agent and determine agent-specific levels in the air. Samples may be collected using large volume air samplers (for all CBRN agents) or by personnel carried small volume air samplers (for chemical and radiological agents).

The sampling staff must be aware of the hazards that may be encountered in the field and take the necessary precautions. Never perform any field activities without proper safety equipment and know how to use it. All monitoring activities are conducted to maintain the lowest level of exposure to the agent. Members of the sampling team must be aware of the possibility of regression of contamination. Monitoring teams must refrain from eating, drinking or smoking in any contaminated area or in areas where monitoring activities are carried out. 
The general scheme of air, smoke and aerosol sampling is as follows: collection of appropriate equipment, preliminary activities (steps 1,2), location of the large and small volume air sampler (step 3), sampling with large and small volume air sampler (steps 4, 5, 6), packaging and administration (step 7) and contamination control/recycling (steps 8,9 ).

\section{Supplies and equipment for sampling.}

Supplies and equipment for sampling include common equipment for all types of samples and equipment for large and small volumes air sampling. The large volume air sampling equipment includes:

- High volume air sampler (at least $100 \mathrm{Lpm}$ or $30 \mathrm{cfm}$ );

- Sampler collection head compatible with filter size (e.g. $47 \mathrm{~mm}$ diameter), clean/sterile;

- Air sampler tripod (one per sampler);

- Filters containing sample collecting media. Depending on the type of medium, there are several types of filters: glass fibre or quartz fibre filters with an initial collection efficiency of 97-99\%, low pressure loss, high flows and good loading capacity, difficult to dissolve, with high alpha self-absorption, can be used to fission product monitoring; polystyrene filter with initial collection efficiency of $99 \%$, moderate pressure loss, high flows and good loading capacity but low mechanical strength; PVC membrane filter with a pore size of $0.03-8 \mu \mathrm{m}$, initial collection efficiency of $99 \%$, moderate pressure loss, useful for silica, carbon black and quartz particles; cellulose filter with a pore size of 1-3 $\mu \mathrm{m}$, initial collection efficiency of $99 \%$, high pressure loss, easy dissolution but fast loading, deteriorate with high moisture, serves to monitor of alpha radiation; polycarbonate membrane filter with a pore size of $0.2-5.5 \mu \mathrm{m}$, initial collection efficiency of $99 \%$, very high pressure loss, excellent surface collection but poor strength and fast dust loading, is used for air sampling in the breathing zone;

- Plastic bags or glassine envelopes (i.e. impermeable) for the sample collecting media (enough for one filter per bag);

- Portable power supply (generator) and fuel;

- Extension cord 20 feet long;

- Tweezers.

Small volume air sampling equipment (for chemical agents and radiological agents in the breathing zone) includes:

- Manual or electric pump to draw the medium through sample tubes (for gas, vapours, liquid aerosols) or filters (for smokes and solid aerosols);

- Sample tubes with end caps and adsorbent material, e.g. Chromosorb 106 or Tenax;

- Air sampling bags such as Tedlar type;

- Sampler collection head compatible with filter size (e.g. $20 \mathrm{~mm}$ diameter); 
- GF/A Whatman filter paper, size is compatible with the collection head.

Other equipment includes plasticizer free, sealable plastic bags or glassine envelopes ( 1 per sample), stopwatch and air sample forms (enough for each filter with collecting medium, C-3 for radiological samples and C-8 for biological and chemical samples).

\section{Preliminary activities.}

Step 1

- Calibration of the air sampler according to the manufacturer's instructions;

- Check the sterility of a large volume air sampler for biological sampling;

- Receive preliminary instructions and assignments from Command;

- Obtain the appropriate equipment;

- Check the performance of the equipment;

- Check the radio;

- Check a GPS.

Step 2 (according to instructions from Command)

- Wrap the instruments (except air samplers) in plastic to prevent contamination (except for the detector window if fitted);

- Set alarm levels of direct-reading dosimeters and dose rate meters in case they need to be used;

- Use of appropriate protective equipment, such as agent blocking drugs, protective clothing, protective masks etc.

\section{Sampling with a large volume air sampler.}

Step 3 (Location and set-up)

- Find an open-air position - away from any objects that could cause turbulence. As a practical rule it is assumed that the air sampler should be located as far away from the building as at least twice the building's height; device;

- Mount the air sampler and secure it with a tripod or other mounting

- Adjust the height of the sampler so that its inlet is approximately $1.5 \mathrm{~m}$ (5 ft) above the ground;

- Properly position the air sampler inlet with the source of the suspect airborne material;

- Record the location of the sampler (ideally in the form of geographical coordinates). Use the appropriate form for air samples.

Step 4 (Installation of a new filter)

- Remove the filter retention frame or filter holder;

- Obtain a clean, weighed filter and record its number;

- Placement of a new filter on the sampling head; 
- Reinstallation of the retention ring or frame.

Step 5 (Collection of air samples)

- Record sampler data (e.g. sampler ID number, sample number, sampler serial number, etc);

- Placement of a small -xII sign (in pencil only) on the outer edge of the exposed side of the filter;

- Turn on the sampler and record the start time and the flow rate on the prepared sample form (either as a rotameter or a similar flow measurement device read and as a corrected flow rate calculated from the calibration chart attached to the air sampler). Do not stand in front of the sampler while work!

Step 6

- Record the rotameter reading and corrected flow rate at the end of the desired collection time (minimum volume is 100:1 for biological and chemical agents and 8,000:1 for radiological agents);

- Turn off the sampler and record the end time and other data on the sample form. Warning! Before proceeding with changes of filters, make sure the sampler device is turned off!; gloves;

- Remove the retention ring of the filter or gasket of the filter faceplate using

- Remove the filter paper from the air sampler by grasping the filter edges using tweezers. For large filters, fold the paper lengthwise with the exposed side to the inside;

- Place the filter paper in a glassine envelope or plastic bag and seal it after removing as much air as possible from the bag. Warning! Turn off unused battery-powered devices to avoid flat batteries, but only when away from the cloud area!

\section{Sampling with a small volume air sampler.}

Step 3 (Location and set-up)

- Locate within 1-2 $\mathrm{m}$ of the contaminated surface at the downwind edge of a contaminated area;

- Properly position the air sampler inlet to the source of suspect airborne material;

- Record the location of the sampler (ideally in the form of geographical coordinates). Use the appropriate form for air samples.

Step 4 (Installation of a new filter or adsorbent tube)

- Remove the paper retention frame (in case of filter) or clamp (in case of tube)

- Record the filter or tube number;

- Place a new filter on the sampling head or a new tube in the sampler orifice;

- Reinstall the retention ring or frame (in case of filter) or clamp (in case of tube). 
Step 5 (Collection of air samples)

- Record the sampler data (e.g. sampler ID number, sample number, sampler serial number etc.);

- Place a small sign (in pencil only) on the outer edge of the exposed side of the filter or at the inlet side of the tube;

- For manually operated pumps: starting pumping and recording the final sample volume on the previously prepared form for air samples. The standard flow rate should be at least $100 \mathrm{ml} / \mathrm{min}$ and the desired volume of the air sample should be at least 1 1.;

- For mechanically operated pumps: turning on the sampler and recording the starting time and the flow rate on the prepared sample form (either as a rotameter or a similar flow measuring device reading and as a corrected flow rate calculated from the calibration chart attached to the air sampler). The standard flow rate should be at least $100 \mathrm{ml} / \mathrm{min}$ and the desired volume of the air sample should be at least 1.5:1. Recording the rotameter reading and corrected flow rate at the end of the desired collection time (minimum collection time is $15 \mathrm{~min}$ ). Turning off the sampler and recording the ending time and other data on the sample form. Do not stand in front of the sampler while working!

\section{Packaging and administration}

\section{Step 6}

Warning! Before proceeding with filter changes, make sure the sampler device is turned off!

- Remove the retention ring of the filter or gasket of the filter faceplate or tube using gloves;

- For filters: remove the filter paper from the air sampler by grasping the filter edges using tweezers. Place the filter paper in a glassine envelope or plastic bag and seal after removing as much air as possible from the bag;

- For tubes: tight closure of tubes using the end caps. Placing the filter paper in a glassine envelope or plastic bag and sealing after removing from the bag as much air as possible.

Step 7 (Completion of the sample delivery form)

Contamination control/recycling.

Step 8

- Visually inspect the sampler, and if necessary, repair or cleaning/sterilization;

- Clean/sterilize the filter head with fluid from a clean source and load a new filter paper if necessary. Clean the tweezers if they are not disposable;

- Refuel the generator for the power supply;

- Make sure that the sample form for the air is properly completed, include the sample and date and time of start and end of the sampling, total sampling time and volume of the sample according to standard conditions. 
Step 9

Finally, check personnel and equipment (contamination control) using A-4 and/or A-8 procedures respectively.

\subsubsection{Water and liquid sampling}

The purpose of water and liquid sampling is to assess the CBRN hazards in drinking water, crops irrigated with water or livestock/wildlife utilizing water in case of a possible attack.

One should record the location of sampling, as well as the environmental conditions at the time of sampling, such as weather conditions, water temperature and flow rate, a kind of a water source etc. If $\mathrm{R}$ agents are suspected, the ambient gamma dose should be measured and recorded.

\section{Equipment}

Equipment that is or might be needed for sampling (depending on the purpose, environment and the agent):

- Equipment common to all sampling protocols (such as: sample position markers, indelible ink pens/writing pad, CBRN hazard labels, disposable plastic sheeting, tissues/paper roll (for cleaning purposes), solvent, alcohol or de-ionised water (for cleaning/decontamination purposes) - in litres, protective clothing, first aid kit, antidote kit, antibiotics and individual decontamination equipment, GPS, maps);

- Equipment specific to biological/chemical/radiological sampling;

- Overshoes, boots, waders;

- Water filters and sampler head for water filters, connective hoses (for B agents);

- Adsorbent cartridges (for R or C agents extracted from water).

For small volume sampling:

- 50-100 ml pipettes (with a balloon pump), syringes (one per sample);

- 50-100 ml sample bottles with lids (one per sample);

For large volume sampling:

- a bucket or a similar container;

- plastic funnels and cylinders;

- a peristaltic pump or other similar device;

- a precipitation sampler;

- tape measure and a stop watch to measure the liquid flow.

Location for sampling and sample size.

- Reservoirs that can be a source of useful water samples are for instance: ponds, lakes, rivers, streams, puddles; any water source in the nearest area of a suspected attack. For all water and liquid samples, the surface samples are most 
preferable. Liquid/water can be taken as a sample as such, or the agents can be extracted according to proper protocols.

- Two sets of samples may turn out to be advantageous for confirmatory second analysis.

- Sample size depends on the suspected CBRN hazard. If the agent concentration is too low, bigger sample volume may be required. On the other hand, big neat agent doses may pose a threat and a safety risk. Typical size of water and liquid samples are given in a Table 1.

Table 1. Typical size of water and liquid samples

\begin{tabular}{|c|c|c|}
\hline \multirow{2}{*}{ Sample type } & \multicolumn{2}{|c|}{ Agent types } \\
\hline & C, B, R & C, B \\
\hline Surface or drinking water & $1-41$ & $50-100 \mathrm{ml}$ \\
\hline Neat or dissolved agent & & $10-50 \mathrm{ml}$ \\
\hline
\end{tabular}

\section{Sampling}

Small scale, direct sampling

1. One pipette or one syringe should be used per sample;

2. Immerse the tip of the syringe or of the pipette just below the liquid surface;

3. Take at least $50 \mathrm{ml}$ of the liquid;

4. Transfer the sample into a clean sample bottle;

5. Close the bottle tightly and proceed to step 2.4 .

Small scale, extractive sampling

1. Install a new filter or adsorbent cartridge prior to collecting the sample:

a) remove a paper retention frame (filter) or clamp (cartridge);

b) write down the filter or cartridge number;

c) place the new filter on the sampler head or put the cartridge in the sampler or syringe orifice;

d) reattach the retention ring or frame (filter) or clamp (cartridge).

2. For collecting the sample use one syringe or one filter per sample.

3. Immerse the pump inlet or the tip of the syringe needle just below the surface and with minimum disturbance.

4. Aspirate minimum $50 \mathrm{ml}$ of liquid.

5. Remember not to use too much pressure to force the liquid through the extractive device!

6. Write down the extracted volume.

7. For filters: carefully remove the wet filter with the tweezers and put it in a sterile capped bottle. 
8. For cartridges: cover with end caps and place in a glassine envelope or a plastic bag and seal, trying to release as much air as possible.

9. Extracted water/liquid should be collected in a clean, sterile bottle, closed tightly.

\section{Large scale, direct sampling}

1. Immerse a collection container (e.g. a bucket) and the sample container in the water and rinse both of them. If using a peristatic pump, pump the water long enough so it can rinse the inside of the whole system accurately.

2. Wear gloves and waders when collecting samples with a bucket or a pump. Carefully submerge them in the water again and let them fill in slowly and continuously but not to the absolute top (samples for a biological analysis require vigorous shaking before taking portions). Avoid collecting bottom sediment, vegetation or small fish, also try to avoid surface disturbance.

3. In case of using a sampler, empty its content slowly into the actual main container using a new, clean funnel. Pour the liquid with minimal disturbance.

\section{Preservation of the sample}

1. The containers should be capped tightly and their exterior surface should be wiped down.

2. Write the sample ID on the sample container using an indelible pen.

3. Preserve the sample - preservation will depend on the agent:

- In case of $\mathrm{R}$ agents, the hydrochloric acid (11 M) must be added to sample bottles, $10 \mathrm{ml}$ per liter of sample, either prior or after sampling, in order to avoid adsorption of radionuclides on the container walls. It is especially important when storage time before analysis may extend (AEP-66, NATO Handbook).

- In case of $B$ and $C$ agents, the protocols are more specific and require more detailed recommendations. Samples must be preserved during the entire mission, including transport to the laboratory in such a way that live agents are not inactivated (e.g. keep cool, airtight containers). Handling techniques must be sterile to avoid cross-contamination.

4. Store the sample bottles at $2-8^{\circ} \mathrm{C}$.

\subsubsection{Environmental samples}

\section{Solids}

Solid environmental samples should be packed in plastic bags or containers. Place each sample in an individual bag. Remove excess void space, seal the bag (self-closure) and further seal by taping. The amount of sample 
required depends upon each specific case, even a very small sample may be of great value.

Soils. Samples should be taken from a surface area of about $10 \mathrm{~cm} \mathrm{x} 10 \mathrm{~cm}$ by scraping a sample from the surface not exceeding $2 \mathrm{~cm}$ depth. Plants, seeds, and debris, when present, should be included. Soil samples from an area suspected of having been contaminated should be collected as soon as possible from the centre of the contaminated area or as close to it as possible. Collect samples from the ground near the bodies of any fallen casualty or dead animal paying particular attention to areas contaminated with fluids expelled from the animal after death. Place soil samples in clean bags, expel excess air and seal the bags. Clean, sterilized, non-breakable glass jars, metal tans or other Teflon-lined containers that can be sealed are also satisfactory.

Stones. Should stones be selected for collection, then these should be of moderate size (about $0.5-2 \mathrm{~cm}$ ), to a total volume of $200-300 \mathrm{ml}$. Place samples in plasticizer-free bags in the same manner as soil samples.

Snow. Samples should be collected from the layer believed to be exposed to a biological attack. Take samples from an area of $10 \mathrm{~cm} \mathrm{x} 10 \mathrm{~cm}$ to a depth of $2 \mathrm{~cm}$. New snow covering the exposed layer would preserve the agents, but should not be collected. The samples should be placed in clean sample bottles and closed with a Teflon-lined lid. Be careful to clean the threads before closing the bottles to prevent melted snow leaking out.

Vegetable matter. At least two litres of vegetation should be collected, preferably from several locations in the target area. Vegetation is an excellent source of absorbed agent especially if sampling is conducted soon after the suspected attack. Leaf samples, particularly from plants that are withering, are preferred. Broad-leafed vegetation is desirable as well as samples of grasses, bushes, and grains. Avoid touching the surface of the leaves with gloves or sampling equipment while gathering the samples. Store vegetation in bags, expel excess air, seal the bags and chill the sample.

Fragments of munitions, canisters, and NBC protective clothing. Munitions remnants and fragments, respirator canisters from protective masks and items of individual NBC protective clothing are highly desirable sources of agent samples. Canisters are particularly useful since they collect particulate agents. It is noted that the location where a canister is found may not be the contaminated site, because the user may have moved after being contaminated.

Non-transportable solid items. Samples from immovable objects such as buildings, walls, paved surfaces or vehicles. These can be sampled by scraping or swabbing the contaminated surface with swabs (cotton, DacronTM, polyester, rayon, and foam). Shafts can be comprised of either wood or plastic. Generally, synthetic swab tips with plastic shafts are recommended because they are not of biological origin and will not interfere with DNA-based detection systems. Swabs may be used dry or wetted with distilled water or phosphate buffered 
saline (PBS) buffer solution. In general, studies have shown that wet swabs have higher collection efficiency than dry swabs. For sampling from the surface we can also use Agar Plates. Agar plates, also known as 'sticky plates', can be used to sample biological agents.

Control Samples. Control samples corresponding to each type of contaminated sample should be taken. The control samples should be packaged and transported in the same manner, along with contaminated samples, ensuring that the possibility of cross contamination is eliminated.

Table 2. Biological Sampling

\begin{tabular}{|c|c|c|c|}
\hline $\begin{array}{l}\text { Type of } \\
\text { Sample }\end{array}$ & Instrumentation & $\begin{array}{l}\text { Quantity of } \\
\text { Sample }\end{array}$ & $\begin{array}{l}\text { Further } \\
\text { Details }\end{array}$ \\
\hline AEROSOL & $\begin{array}{l}\text { Sterile biolog- } \\
\text { ical } \\
\text { aerosol sampling } \\
\text { unit or high } \\
\text { volume } \\
\text { cyclone }\end{array}$ & $\begin{array}{l}\text { As produced } \\
(\min 1001)\end{array}$ & $\begin{array}{l}\text { Only when positive } \\
\text { indication is received } \\
\text { from detection } \\
\text { equipment }\end{array}$ \\
\hline SOLID & $\begin{array}{l}\text { Tongs/forceps/ } \\
\text { scoop }\end{array}$ & $\begin{array}{l}\text { Stones. Only those of } \\
\text { moderate size (about } \\
0.5-2 \mathrm{~cm} \text { ) should be } \\
\text { selected to a maximum } \\
\text { volume of } 200-300 \mathrm{ml}\end{array}$ & $\begin{array}{l}\text { Stones, plastics, } \\
\text { metals etc. } \\
\text { Sizes of sample - a range } \\
\text { of } 0.5-2 \mathrm{~cm}\end{array}$ \\
\hline SNOW & Scoop & $\begin{array}{l}\text { An area of } \\
10 \mathrm{~cm} \times 10 \mathrm{~cm} \times 2 \mathrm{~cm} \\
\text { deep }\end{array}$ & $\begin{array}{l}\text { Collect only layer ex- } \\
\text { posed to attack }\end{array}$ \\
\hline SOIL & Scoop & $\begin{array}{l}\text { An area of } \\
10 \mathrm{~cm} \times 10 \mathrm{~cm} \times 2 \mathrm{~cm} \\
\text { deep }\end{array}$ & $\begin{array}{l}\text { Sandy soil is easier to } \\
\text { analyse }\end{array}$ \\
\hline WATER & $\begin{array}{l}\text { Pipettes, syring- } \\
\text { es, \& vacuum } \\
\text { containers }\end{array}$ & $100 \mathrm{ml}$ & Surface liquid \\
\hline LIQUID & $\begin{array}{l}\text { Vacutainers, pi- } \\
\text { pettes, syringes }\end{array}$ & $10 \mathrm{ml}$ & Neat agents \\
\hline $\begin{array}{l}\text { CANIS- } \\
\text { TERS, NBC } \\
\text { CLOTH- } \\
\text { ING }\end{array}$ & $\begin{array}{l}\text { Tongs/forceps, } \\
\text { scissors and } \\
\text { scalpel }\end{array}$ & $\begin{array}{l}\text { Any amount to be placed } \\
\text { in } 500 \mathrm{ml} \text { bags }\end{array}$ & $\begin{array}{l}\text { Canisters trap } \\
\text { agents }\end{array}$ \\
\hline
\end{tabular}


Table 2. cont.

\begin{tabular}{|l|l|l|l|}
\hline \multicolumn{1}{|c|}{$\begin{array}{c}\text { Type of } \\
\text { Sample }\end{array}$} & Instrumentation & \multicolumn{1}{|c|}{$\begin{array}{c}\text { Quantity of } \\
\text { Sample }\end{array}$} & \multicolumn{1}{c|}{$\begin{array}{c}\text { Further } \\
\text { Details }\end{array}$} \\
\hline $\begin{array}{l}\text { UN-TRANS- } \\
\text { PORT- } \\
\text { ABLE } \\
\text { SOLID } \\
\text { ITEMS }\end{array}$ & $\begin{array}{l}\text { Dry cotton } \\
\text { wool/cotton } \\
\text { wool soaked in } \\
\text { distilled water } \\
\text { or PBS/swabs } \\
\text { with transport } \\
\text { media }\end{array}$ & Any numbers & $\begin{array}{l}\text { Samples taken by } \\
\text { scraping and/or } \\
\text { swabbing }\end{array}$ \\
\hline $\begin{array}{l}\text { VEGETA- } \\
\text { TION }\end{array}$ & $\begin{array}{l}\text { Tongs/forceps, } \\
\text { scissors \& seca- } \\
\text { teurs }\end{array}$ & 21 & $\begin{array}{l}\text { Broad-leafed plants } \\
\text { are preferred }\end{array}$ \\
\hline $\begin{array}{l}\text { URBAN } \\
\text { SAM- } \\
\text { PLING }\end{array}$ & $\begin{array}{l}\text { Sterile dry } \\
\text { rayon/cotton } \\
\text { swabs or cotton } \\
\text { tipped sticks in } \\
\text { a storage tube } \\
\text { with transport } \\
\text { medium, cloth } \\
\text { discs or filter pa- } \\
\text { per wetted with } \\
\text { sterile water }\end{array}$ & Area for smear $100 \mathrm{~cm}^{2}$ & Flat surface swabs \\
& & \\
\end{tabular}

\section{Biomedical Samples}

Dead Animals. If the carcass is small, collect and ship it complete, refrigerated where possible. Place samples in plasticizer-free bags or sterilized containers. If the dead organism is large, useful samples may be taken from the spleen, kidney, the liver, the lungs, the skin, the muscles, the blood from the heart, the lymph nodes, small bones and the brain. Arthropod vectors of disease such as mosquitoes, fleas, ticks, lice etc. should be collected in large numbers.

Human Casualties. Normally, casualties of suspected biological attacks would be taken to medical facilities where appropriate equipment is available to collect samples of physiological fluids, tissues, etc. Therefore, such equipment has not been included in the field sampling kits.

The following samples may be taken from human casualties:

1. Blood. Blood samples from casualties should be taken by vacuum syringe (Vacutainer). The sample tubes must be sterile; i.e. hermetically sealed with a plastic plug which can be pierced readily. Blood samples should be kept 
cold but NOT frozen. The following blood samples should be taken from each casualty:

- $1 \times 10 \mathrm{ml}$ into an uncoated sterile tube;

- $2 \times 10 \mathrm{ml}$ into tubes with sodium heparin;

- $1 \times 10 \mathrm{ml}$ into a tube with EDTA (disodium Salt);

- $1 \times 10 \mathrm{ml}$ into a tube with sodium citrate.

2. Urine. Urine samples of $100-200 \mathrm{ml}$ volume should be taken into sterile glass or plastic containers. Collection of urine over an extended period (up to 2448 hours) is also desirable. Biomedical samples (blood/urine) should be taken as soon as possible after the exposure to agents, preferably within 72 hours.

3. Skin. Swab samples from skin, small samples of the affected area should be taken, along with fluid from any blisters. Skin is best stored on ice.

4. Mucous Membranes. Swab samples from the mucous membranes and the nasopharynx should be taken.

5. Saliva, Vomit and Excrement. Since samples of this type are usually of little value, they should not be taken unless there is a particular reason for it. Samples should be taken into sterile glass containers.

Table 3. Biomedical sampling

\begin{tabular}{|c|c|c|c|}
\hline $\begin{array}{l}\text { Type of } \\
\text { Sample }\end{array}$ & Instrumentation & $\begin{array}{l}\text { Quantity } \\
\text { of Sample }\end{array}$ & $\begin{array}{c}\text { Details } \\
\text { of Sample }\end{array}$ \\
\hline $\begin{array}{l}\text { DEAD } \\
\text { ANIMALS }\end{array}$ & Tools & $\begin{array}{l}\text { Whole carcass or relevant } \\
\text { parts thereof. }\end{array}$ & \\
\hline $\begin{array}{l}\text { HUMAN } \\
\text { BLOOD }\end{array}$ & $\begin{array}{l}\text { Venojet or } \\
\text { vacuum syringe } \\
\text { system }\end{array}$ & $\begin{array}{l}1 \times 10 \mathrm{ml} \text { into a sterile tube. } \\
2 \times 10 \mathrm{ml} \text { coated by sodium } \\
\text { by medical corps heparin. } \\
1 \times 10 \mathrm{ml} \text { in tube coated with } \\
\text { EDTA. } \\
1 \times 10 \mathrm{ml} \text { in tube coated in } \\
\text { sodium citrate. }\end{array}$ & $\begin{array}{l}\text { Only to be } \\
\text { taken by } \\
\text { medical corps } \\
\text { personnel. }\end{array}$ \\
\hline $\begin{array}{l}\text { HUMAN } \\
\text { URINE }\end{array}$ & $\begin{array}{l}\text { Sterile glass or } \\
\text { plastic container }\end{array}$ & $100-200 \mathrm{ml}$ & \\
\hline SKIN & Swabs & Swab samples & \\
\hline $\begin{array}{l}\text { MUCOUS } \\
\text { MEMBRANES }\end{array}$ & Swabs & Swab samples & $\begin{array}{l}\text { Eyes, naso- } \\
\text { pharynx. }\end{array}$ \\
\hline $\begin{array}{l}\text { SALIVA, VOM- } \\
\text { IT AND EX- } \\
\text { CREMENT }\end{array}$ & $\begin{array}{l}\text { Sterile glass } \\
\text { container }\end{array}$ & volume possible to download & \\
\hline
\end{tabular}




\subsection{Biological Sampling Equipment}

\section{Use of Sampling Equipment in the Field}

Samples should be collected and handled with clean (in the case of biological agents: sterile) forceps, spatulas, scoops, scissors, scalpels, and other sampling instruments. Sufficient quantities of handling devices are to be available, to avoid re-use of the instruments in the collection of more than one sample. This minimizes the risk of contamination transfer from gloves to samples or from one sample to another.

Sampling equipment should be scrupulously clean (sterile for biological agents) and it should be stored in clean (sterile) bags prior to the mission.

\section{General equipment:}

- $60 \mathrm{x}$ sealable zip bags (various sizes);

- $10 \times 50 \mathrm{ml}$ sterile wide necked glass or plastic bottles (air tight);

- 6 × $250 \mathrm{ml}$ sterile wide necked glass or plastic bottles (air tight);

- 4 x transport bags (50 1);

- $1 \times$ tissue container;

- $50 \mathrm{x}$ sheets for description of samples;

- $5 \mathrm{x}$ pairs NBC gloves;

- $1 \mathrm{x}$ bottle of sodium hypochlorite solution (IZ-15\% chlorine) or similar disinfectant;

- $1 \mathrm{x}$ bottle of distilled water;

- $1 \mathrm{x}$ bottle of phosphate buffered saline (PBS);

- 10 x swabs;

- 1 x roll sealing tape (parafilm);

$-2 \mathrm{x}$ marker pens (waterproof);

- disinfectant-impregnated absorbent material for transport packaging;

- $1 \mathrm{x}$ bag sealer (portable);

- $1 x$ portable refrigerator unit powered by battery and capable of maintaining $2-8^{\circ} \mathrm{C}$.

\section{Additional Equipment for Environmental Sampling:}

For sampling solids:

- Sterile tongs, secateurs and scissors (large);

- Sterile scalpels and spare blades;

- $12 \mathrm{x}$ sterile spoon spatulas;

- $5 \mathrm{x}$ sterile disposable forceps; 
- Spade/shovel (small);

- Disposable scoops (plastic; e.g., $100 \mathrm{ml}, 200 \mathrm{ml}$ );

- 1 x roll aluminium foil;

- 50-100 ml sample bottles, with Teflon-lined, airtight lids (for snow samples, one per sample);

- Large, sealable bags or glassine envelopes or 2-4 1 plasticizer free plastic jugs with cap (for solids and objects; one per sample);

- Environmental sample forms and sample custody forms (one per sample).

For sampling surfaces:

- $10 \mathrm{x}$ sterile dry rayon swabs;

- $10 \mathrm{x}$ sterile swabs in microbiological transport medium;

- $100 \mathrm{ml}$ phosphate buffered saline.

For sampling liquids:

- 12 x sampling needles (18 gauge blunt);

- $12 \mathrm{x}$ pipettes $(50-100 \mathrm{ml})$.

For sampling air:

- $10 \mathrm{x}$ aerosol sampling filters assemblies, capacity 20 litres $/$ minute $(5-10 \mathrm{~cm}$ diameter);

- or hand-held aerosol impinger of the same air capacity;

- $1 \mathrm{x}$ bottle of distilled water.

For sampling surfaces:

- $10 \mathrm{x}$ sterile dry rayon swabs;

- $10 \mathrm{x}$ sterile swabs in microbiological transport medium;

- $100 \mathrm{ml}$ phosphate buffered saline.

For sampling liquids:

- $12 \mathrm{x}$ sampling needles (18 gauge blunt);

- $12 \times$ pipettes $(50-100 \mathrm{ml})$.

For sampling air:

- $10 \mathrm{x}$ aerosol sampling filters assemblies, capacity 20 litres $/$ minute $(5-10 \mathrm{~cm}$ diameter);

- or hand-held aerosol impinger of the same air capacity;

- $1 \mathrm{x}$ bottle of distilled water.

\section{Additional Equipment for Biomedical Sampling}

- $1 \mathrm{x}$ small tool kit;

- $1 \mathrm{x}$ thermometer (digital);

- $1 \mathrm{x}$ water sampling kit consisting of 
- $50 \times 10 \mathrm{ml}$ evacuated flasks (sterile, silicone coated);

- $50 \mathrm{x}$ double-ended sterile needles (18 gauge fitted with safety caps);

- $6 \mathrm{x}$ sterile blunt ended needles for insertion into sampler tubing;

- $6 \times$ sterile sampler tubing (weighted) - $(3 \times 25 \mathrm{~cm} ; 3 \times 100 \mathrm{~cm})$;

- $1 \mathrm{x}$ rack for evacuated tubes.

- $1 \mathrm{x}$ medical sampling kit for taking of pathological specimens;

- 1 x entomological kit;

- 1 x blood sampling kit consisting of:

- $50 \mathrm{x}$ vacutainer $(10 \mathrm{ml})$;

- $100 \mathrm{x}$ un- and pre-coated tubes;

- $50 \mathrm{x}$ double-ended sterile needles fitted with safety caps;

- $6 \mathrm{x}$ sterile blunt ended needles for insertion into sampler tubing;

- 6 x sterile sampler tubing $(3 \times 25 \mathrm{~cm}, 3 \times 100 \mathrm{~cm})$;

- $1 \mathrm{x}$ rack for evacuated tubes.

\subsection{Labelling and documentation of samples}

The samples should be labelled and forwarded for analysis as expeditiously as possible through appropriate national channels.

Labels should be affixed to each sample container. On each should appear a code number which clearly and uniquely refers to the accompanying the nature and circumstances of collection. If on-site contamination checks reveal the presence of a toxic substance, this should be clearly indicated on the sample containers by means of colour coding and/or a highly visible internationally recognized hazard symbol. Labelling should not contaminate the sample and should be sufficiently resistant to degradation, decontamination.

All aspects of sample collection, packaging, storage and transportation must be documented (Data sheet).

\subsection{Sampling based on autonomous or remote controlled ground or aerial vehicles}

The crucial point in eliminating or reducing the number of casualties and reducing the spread of $\mathrm{CB}$ warfare contaminations is how quickly they are detected. The key issue is also safety of sampling. Current biological detection system can detect only a limited number of biological agents and only after exposure. Sensitivity, selectivity and durability of these detection technologies demand of perfection.

The goals of detection system include the following:

1) to detect agents in time to warn, protect and minimize the number of casualties;

2) to identify agents in time to initiate medical therapies on casualties; 
3) to collect samples for verification.

The overall goal of a detection system should be: detection of agents in sufficient time to warn, protect and minimize the number of casualties among those who would be exposed to the agents, identification of agents and possibility for independent verification of identification. The generic model for a point detection system will include four elements; a collector, a trigger, a detector, and an identifier. The trigger component provides non-specific detection of the presence of possibly harmful biological material. The trigger component should give a rapid indication of the likely presence, but not the identity, of biological material and normally bases this indication on a change in the background conditions.

The detector component determines the presence of categories of biological agents, but may not provide sufficiently specific information on which to base protective or treatment decisions. The identifier component, as the name implies, identifies the specific BW agent to the degree necessary to allow commanders to initiate appropriate protective measures.

The groundwork of proper identification and possibility of use of suitable method is sampling. Biological sampling is normally targeted at living organisms, so the sampling technique must preserve and not harm the collected sample. Most biological detection and presumptive and confirmatory identification technologies require a liquid sample, so the collection must be from an aerosol or particulate onto a liquid. The liquid sample must be highly concentrated and available for analysis rapidly.

The word 'sampling' is usually taken to mean the collection of a large volume of air and concentrating the particulate matter in either an air or fluid medium so as to prepare a 'sample' for further investigation and analysis. Hundreds of litres of air are normally required to obtain an adequate sample of material, and the collection device must be able to gather that much air and aerosol.

\subsubsection{Sampling based on unmanned ground vehicle}

Unmanned ground vehicle (UGV) is a vehicle that operates without human presence on the board and in contact with the ground. It can be used in many applications especially in dangerous environment or when human operator presence is impossible. UGV can be used as an autonomously or remote controlled devices. An autonomous UGV is essentially an autonomous robot that operates without the need for a human controller. The vehicle uses its sensors to develop some limited understanding of the environment, which is then used by control algorithms to determine the next action to take in the context of a human provided mission goal. This fully eliminates the need for any human to watch over the menial tasks that the UGV is completing. Autonomous 
UGV travel between way points without human navigation assistance. It can also help to aim according to GPS data.

For biological sampling autonomous UGV can be used to take a sample of aerosol after triggering and detection of aerosol cloud. On the platform of UGV should be mounted devices for triggering and detection of biological agents (i.e. Fluorescence and Particle Sizing, Size and Shape Analysis, Pyrolysis/Gas Chromatography/Ion Mobility Spectrometry, Chemical Luminescence, Flame Photometry/Gas Chromatography, Flow Cytometry, Mass Spectrometry). Proper taking of aerosol samples for identification of an agent requires the use of a cyclone-based working device. Aerosol particles are collected in the liquid phase and transferred to the lab.

\subsubsection{Sampling based on remotely operated ground vehicles}

Remotely operated ground vehicle (ROGV) needs human operator who radio-manages the action observing it on the monitor. ROGV has devices for sampling of air, ground, water and other little objects like stones or suspicious tanks installed on the board. Contamination of air can have forms of aerosol or mist Aerosol is dispersion in air of solid particles of microscopic size. Mist is dispersion in air of liquid droplets usually large enough to be seen by the naked eye. For air sampling commonly instruments working on the base of cyclone are used. One-time this instrument aspirates about $10 \mathrm{~m}^{3}$ of air and suspends solid particles in $30-50 \mathrm{ml}$ of liquid phase. The sample is transferred for tests carried out by devices on ROGV or in the stable laboratory after it's back. Results of examination carried out on the ROGV are send by radio to the basic laboratory.

Liquid samples (water or other liquids) are taken by special devices mounted on ROGV working as a pomp. These samples should be taken to sterile containers and examined by devices on ROGV or/and after back in stable laboratory. Required volume of liquid sample - c.a. $100 \mathrm{ml}$.

On the platform of ROGV a special device working as an digger can take a sample of ground. The sample is transferred to sterile plastic bag and transported to the basic laboratory. For taking other samples like stones, vegetables, small dead animals, ROGV should be equipped with special claws enabling of drawing such material and packing it to special plastic bags. ROGV should be equipped with facilities for disinfection and ability for self-disinfection before back to the basic laboratory. Required weight of soil sample - c.a. $100 \mathrm{~g}$.

\subsubsection{Remote Controlled Aerial Vehicles (RCAV) - Drones}

UAVs (Unmanned Aerial Vehicles) are a component of Unmanned Aircraft Systems (UAS), which consist of a UAV, a ground-based controller, 
and a system of communications between the two. UAV may operate under remote control by a human operator or autonomously by on-board computers. Drones may be used for aerosol sampling only if there is a possibility to install a miniaturized cyclone-type device to suspend the aerosol particles in liquid. The sample should be taken to the basic laboratory. Drones must be disinfected in the place of landing. Drones are dispatched directly to the aerosol cloud (detected by other methods) and sample of 1 cubic meter taken by cyclone apparatus seems to be adequate for identification of a biological agent in laboratory.

\subsection{Field exercises - environmental sampling for the presence of biological weapons}

\section{Location for solids and soil sampling}

The best location for sampling will be where casualties have occurred or where there may be wilted or discoloured plants or an unusual number of dead animals such as fish, birds or rodents. Soil, snow, vegetation and solid samples should be from a highly contaminated area or from near a casualty.

\subsubsection{Sampling of stones}

Collecting the sample:

- Select stones of moderate size (about $0.5-2 \mathrm{~cm}$ ) should be selected to a maximum volume of $200-300 \mathrm{ml}$;

- Use clean/sterile tweezers or thongs to place the stones in plasticizer free, clean/sterile bags or in plasticizer free jugs;

- Seal the bag, or close the jug airtight;

- Store the sample preferably at $2-8^{\circ} \mathrm{C}$.

\subsubsection{Sampling of soil}

Collecting the sample:

- Use one disposable scoop per sample or use a cleaned spade/shovel;

- Take a sample over a surface area of about $10 \mathrm{~cm} \times 10 \mathrm{~cm}$ by scraping material from the surface, not exceeding $2 \mathrm{~cm}$ depth. Plants, seeds, and debris, when present, should be included;

- Transfer the soil sample into a clean (sterile) bag or sample bottle;

- Seal the bag, or close the sample bottle airtight with a Teflon lined lid;

- Store the sample preferably at $2-8^{\circ} \mathrm{C}$. 


\subsubsection{Sampling of snow}

Collecting the sample:

- Use one disposable scoop per sample or use a cleaned spade/shovel;

- Collect a sample from the layer believed to be exposed to an attack. Take samples from an area of $10 \mathrm{~cm} \times 10 \mathrm{~cm}$ to a depth of $2 \mathrm{~cm}$;

- Transfer the snow sample into a clean (sterile) sample bottle;

- Close the sample bottle airtight with a Teflon lined lid;

- Store the sample preferably at $2-8^{\circ} \mathrm{C}$.

NOTE. New snow covering the exposed layer would preserve the agents, but should not be collected.

\subsubsection{Sampling of vegetable matter}

Collecting the sample:

- Use one disposable scoop per sample or use a cleaned spade/shovel;

- Collect at least two litres of vegetation, preferably from several locations in the target area. Broad-leaved vegetation as well as samples of grasses, bushes and grains should be collected;

- Transfer sample material into a clean (sterile) bag or sample bottle;

- Seal the bag, or close the sample bottle airtight with a Teflon lined lid;

- Store the sample preferably at $2-8^{\circ} \mathrm{C}$.

NOTE. Avoid touching the surface of leaves with gloves or sampling equipment while gathering the samples.

\section{References}

Biological Incident Response \& Environmental Sampling - a European Guideline on Principles of Field Investigation, EU Commission, DG Health and Consumer Protection, Health Threats Unit, October 2006.

Blatny J.M., Fykse E.M., Olsen J.S., Skogan G., Forsvarets T.A., Identification of biological threat agents in the environment and its challenge, Norwegian Defence Research Establishment (FFI) July $15^{\text {th }} 2008$.

Chen J.Y.C., UAV-guided navigation for ground robot tele-operation in a military reconnaissance environment, Journal of Ergonomics 2010, no. 53.

Crosby N.T., Patel I., General principles of good sampling practice, Royal Society of Chemistry 1995, Vol. 1.

Duan H.B., Liu S.Q. Unmanned air/ground vehicles heterogeneous cooperative techniques: Current status and prospects, Science China Technological Sciences 2010, no. 53.

Fykse E., Aarskaug T., Byström M., Gebert S., Report on protocols for sample preparation and identification analysis of biological threat agents, Norwegian Defence Research Establishment 2013. 
Giesbrecht J., Global Path Planning for Unmanned Ground Vehicles, Defence R\&D Canada - Suffield Technical Memorandum DRDC Suffield TM 2004-272 December 2004.

Gupta S.G., Ghonge M.M., Jawandhi P.M., Review of Unmanned Aircraft System (UAS), International Journal of Advanced Research in Computer Engineering \& Technology (IJARCET) 2013, no. 2.

Hancock J.R., Dragon D.C., Sample Preparation and Identification of Biological, Chemical and Mid-Spectrum Agents, A General Survey for the Revised NATO AC/225 (LG/7) AEP-IO Edition 6 Handbook, Canada 2005.

NATO Handbook for Sampling and Identification of Biological, Chemical and Radiological Agents (SIBCRA). Edition A, Version 1; NATO Standard AEP-66. Published by the NATO Standardization Agency (NSA).

NATO, AEP-10: NATO Handbook for Sampling and Identification of Biological, Chemical and Radiological Agents - Volume 1 Procedures and Techniques; NATO, June 1, 2000.

NATO, AAP-21: NATO Glossary of Chemical, Biological, Radiological and Nuclear Terms and Definitions (English and French). AAP-21(2006). Brussels, Belgium: NATO.

NATO, AEP-45: Warning and Reporting and Hazard Prediction of Chemical, Biological, Radiological and Nuclear Incidents (Reference Manual). STANAG 2497. Brussels, Belgium: NATO, January 8, 2015.

NATO, AEP-72: Recommended Chemical, Biological and TIC Challenge Levels. STANREC 4726. Brussels, Belgium: NATO, September 1, 2014.

Nygren M., Strand Olsen J., van der Schans M., Rivier C., Griffith M., Duarte Davidsson R., Stöven S., Report on the concept of analysing unknown samples, 2013.

Ozanich R.M., Colburn H.A., Baird C.L., Straub T.M., Bartholomew R.A., Bruckner-Lea C.J., Biodetection Technologies for First Responders: 2014 Edition,USA, Washington March 2014. 